\title{
CAN TEACHERS IDENTIFY CHILDREN WHO NEED MORE HELP TO BE PHYSICALLY ACTIVE?
}

\author{
N.K. Mullan ${ }^{1}$, L.A. McWilliams ${ }^{1}$, D. Nathan ${ }^{2}$, I.A. MacDonald ${ }^{3}$, I. Smyth ${ }^{4}$, M. Batty ${ }^{5}$, C. Glazebrook ${ }^{1}$ \\ ${ }^{1}$ Division of Psychiatry - Behavioural Sciences, University of Nottingham, ${ }^{2}$ Nottingham University Hospitals \\ NHS Trust, ${ }^{3}$ School of Biomedical Sciences, ${ }^{4}$ Child Health, ${ }^{5}$ Developmental Psychiatry, University of \\ Nottingham, Nottingham, UK
}

Background and aims: Identifying primary school children who are not sufficiently active will permit timely intervention by parents, schools and healthcare professionals. This study aims to investigate the accuracy of teachers' ratings of children's body size and barriers to participation in physical activities.

Methods: Teachers rated body shape in 1021 children aged 9-11 using the Child Body Image Scale (consisting of representations of boys and girls at different weight centiles). They also indicated if the child lacked confidence during P.E. lessons or, in contrast, could be considered 'sporty'. Children rated their willingness to engage in physical activity using the Predilection sub-scale of the Children's Self-Perceptions of Adequacy in and Predilection toward Physical Activity scale (CSAPPA).

Results: Teachers identified 161 children (16\%) in whom they felt low confidence was a barrier to exercise and these children had significantly lower scores on the predilection subscale of the CSAPPA $(\mathrm{p}<0.001)$. Children rated as sporty by teachers, in contrast, had significantly higher scores on the CSAPPA $(p<0.001)$. Seventy-two children were rated above the $75^{\text {th }}$ centile, 29 boys and 43 girls. Consent was obtained to measure actual weight and height in 176 children (74 boys; 102 girls). A strong agreement was found between teacher ratings of centiles and child BMI in both boys $(\mathrm{ICC}=0.85 ; \mathrm{p}<0.001)$ and girls $(\mathrm{ICC}=0.89$; $\mathrm{p}<0.001)$.

Conclusions: Teacher identification of children who are overweight and have low confidence is both feasible and valid enabling targeted interventions to be tailored to the school setting. 